\title{
Life in two dimensions or keeping your head down: Lateral exuvial splits in leaf-mining larvae of Pachyschelus (Coleoptera: Buprestidae) and Cameraria (Lepidoptera: Gracillariidae)
}

\author{
VASILY V. GREBENNIKOV \\ Ottawa Plant Laboratory, Canadian Food Inspection Agency, K.W. Neatby Bldg., 960 Carling Ave., Ottawa, ON, K1A 0C6, \\ Canada; e-mail: vasily.grebennikov@inspection.gc.ca
}

Key words. Leaf-mining, moult, exuviae, larvae, Buprestidae, Pachyschelus, Gracillariidae, Cameraria

\begin{abstract}
This paper describes previously unreported lateral cuticle splits occurring during the moulting of larvae of the leaf-miners Pachyschelus laevigatus (Say, 1839) (Coleoptera: Buprestidae) and Cameraria sp. (Lepidoptera: Gracillariidae). In these species the cuticle does not split dorsally during the larval/larval moults as in most insects, but laterally, thus permitting the larva to leave its exuviae sideways rather than vertically. This previously overlooked phenomenon is hypothesized to have evolved independently in both taxa and is an adaptation to life in the vertically limited space of their mines and, therefore, might be found in other organisms confined to similar conditions. The exuvial split in the larva to pupa moult of Cameraria sp. taking place inside a relatively tick and firm cocoon is, however, of the regular dorso-medial type, and, therefore, two different successive types of moult occur within a single ontogenesis. For comparative purposes the common dorsal exuvial split is described and illustrated for the leaf-mining larvae of Profenusa alumna (Hymenoptera: Tenthredinidae), Sumitrosis rosea (Coleoptera: Chrysomelidae) and the free-living Satonius fui (Coleoptera: Torridincolidae).
\end{abstract}

\section{INTRODUCTION}

The necessity to split and shed their outgrown cuticle is one of the most universal challenges repeatedly faced by nearly all immature individuals of Arthropoda and other phyla of the Ecdysozoa. Details of the moulting process are highly conservative and differences are seen only among the major phylogenetic lineages. In Insecta, and particularly in the Holometabola clade, the newly emerging larvae almost universally leave the shed cuticle through a single exuvial opening along the dorso-medial line.

This paper reports, describes and illustrates the apparently first documented case of a lateral split in the exuviae of the larvae of the leaf miners Pachyschelus (Coleoptera: Buprestidae) and Cameraria (Lepidoptera: Gracillariidae). It further relates this phenomenon to the limitations imposed by the leaf-mining life style within the phylogenetic context of the four major holometabolan orders: Coleoptera, Lepidoptera, Diptera and Hymenoptera.

\section{MATERIAL AND METHODS}

Pachyschelus laevigatus (Coleoptera: Buprestidae) (Fig. 1): on Desmodium glutinosum (Muhl. ex Willd.) (Fabaceae), Canada, Quebec, Gatineau Park along Luskville Falls trail, $45^{\circ} 32^{\prime} 00^{\prime \prime} \mathrm{N}, 075^{\circ} 59^{\prime} 39^{\prime \prime} \mathrm{W}, 88 \mathrm{~m}$, August-September 2008 (together with Sumitrosis rosea; see below).

Cameraria spp. (Lepidoptera: Gracillariidae): adult of Cameraria gaultheriella Walsingham, 1889 (Fig. 2A) collected in Richmond Nature Park, British Columbia, Canada; larvae, exuviae and pupae (Figs 2B-P) from and in mines in leaves of Acer L. (Sapindaceae), Quercus L. (Fagaceae) and Ostrya virginiana (Mill.) K. Koch (Betulaceae), Canada, Quebec, Bristol Mines, $45^{\circ} 29^{\prime} 24^{\prime \prime} \mathrm{N}, 076^{\circ} 23^{\prime} 18^{\prime \prime} \mathrm{W}, 72 \mathrm{~m}$, August 2008 and August 2012 (together with Profenusa alumna; see below).
For comparative purposes, two additional leaf-mining and one non leaf-mining holometabolan species with the orthodox dorsal exuvial split were studied and illustrated:

Profenusa alumna (MacGillivray, 1923) (Hymenoptera: Tenthredinidae): two exuviae (Figs 3A-D) from inside abandoned leaf-mines on red oak (Quercus rubra L.) together with Cameraria spp. (see above); adult (Fig. 3E), USA, Maine, Canton, 29.vi.1965.

Sumitrosis rosea (Weber, 1801) (Coleoptera: Chrysomelidae: Cassidinae): exuviae (Fig. 3J), larvae (Figs $3 \mathrm{~K}-\mathrm{N}$ ), and pupae inside leaf-mines on $D$. glutinosum together with $P$. laevigatus (see above); teneral adult (Fig. 3O) reared in laboratory.

Satonius fui Hájek, Yoshitomi, Fikáček, Hayashi et Jia, 2011 (Coleoptera: Torridincolidae; a randomly chosen non-leafmining species), single shed cuticle (Figs $3 \mathrm{~F}-\mathrm{H}$ ), together with numerous adults and larvae, P.R. China, Hubei, Dabie Shan, $31^{\circ} 06^{\prime} 31^{\prime \prime} \mathrm{N}, 115^{\circ} 48^{\prime} 30^{\prime \prime} \mathrm{E}, 750 \mathrm{~m}$, June 2008; S. stysi Hájek \& Fikáček, 2008, adult (Fig. 3I), P.R. China, Yunnan, Cang Shan, $25^{\circ} 40^{\prime} 17^{\prime \prime} \mathrm{N} 100^{\circ} 07^{\prime} 47^{\prime \prime} \mathrm{E}, 2,700 \mathrm{~m}$, 3.vii.2011.

Observations on Pachyschelus beetles lasted for about three hours in the field and five hours in the laboratory and on Cameraria five and five hours, respectively. Cameraria mines, originally collected from red oak ( $Q$. rubra L.), were subsequently collected and studied from a variety of trees and shrubs around Ottawa, where more than one Cameraria species are known to occur and, therefore, the observations cited below may be for a mix of congeneric species. Since similarly shed exuviae were found in all the Cameraria mines on different host plants, it is assumed that the observations reported below are applicable to all Cameraria species, or at least those known from around Ottawa. Image-based generic identification of Cameraria larvae was originally suggested by D.R. Davis (Washington, DC, USA) and later corroborated by genetic barcoding of a larval specimen (Genbank accession number JX441883) showing less than $1 \%$ genetic differences compared with the two genetically most similar Cameraria species: C. bethunella (Chambers, 
1871) and C. ostryarella (Chambers, 1871). Exuviae of the sawfly Profenusa alumna (Figs 3A-D) were identified by $\mathrm{H}$. Goulet (Ottawa, Canada).

Mines were opened, studied and photographed under a Nikon SMZ1500 dissecting microscope with an attached digital camera Nikon DXM1200F, while Figs 1A, B, 2B, C were taken in the field with a hand-held digital camera. Fig. 1L was assembled from two separate images taken from a shed cuticle mounted on a microscope slide in Canada balsam and then joined digitally. Terms denoting morphologically and behaviourally different subsequent instars of Gracillariidae caterpillars ("sap-feeding", "spinning" and "quiescent") follow Kumata (1978).

\section{RESULTS}

Leaf-mining larvae of both the species observed, a buprestid beetle and a gracillariid moth, have a number of morphological and behavioural features in common, such as (1) larvae are markedly flattened and lack articulated thoracic legs; (2) there was little or no frass close to egg shells and no conspicuous entrance to the leaf mine, suggesting that newly hatched larvae enter the leaf by biting directly through the egg chorion into the leaf surface (Figs 1H, 2D); (3) larvae were not observed outside mines; (4) larvae fed almost constantly by employing markedly prognathous mouthparts and occasionally moving the anterior part of their body from side to side to access a new food supply; when doing so the posterior part of their body was firmly wedged between dorsal and ventral internal leaf surfaces. The exact number of larval instars could not be determined, although in both species it appears to be no less than three. The last larval instars of both Pachyschelus (Fig. 1K) and Cameraria (Figs 2N, O) are morphologically different from the preceding ones, being markedly less flattened.

\section{Pachyschelus laevigatus (Coleoptera: Buprestidae)}

Linear mines always contained an individual larva with its head deeply retracted into the prothorax and almost invisible externally, except for the mouthparts (Figs 1C, $\mathrm{M})$. Normally there was only one mine per leaf, but a few cases of two mines per leaf were recorded. Mine landmarks included sites where adults had nibbled the surface of a leaf (Fig. 1H), centrally-located larval faecal trail (Fig. 1D), moulting chambers containing shed exuviae (Fig. 1D) and, occasionally, a parasitoid near or on a larva (Fig. 1D). A chamber was seen containing a last larval instar (Fig. 1K), but no pupae were observed. Adults were occasionally seen either flying or sitting on the leaves of the host plant (Fig. 1B). When mines were detected on a host plant $10 \%$ or less of the leaves were mined. The larva to pupa moult was not observed and the cuticular split may be different from the larva to larva moult described below.

Two larvae were observed and photographed during the process of moulting (Figs $1 \mathrm{E}-\mathrm{G}, \mathrm{J}$ ). The exuvial head remained intact, did not split along its sutures and was deeply retracted into and firmly attached to the exuvial prothorax (Fig. 1L). The entire cuticle split along both sides from the mesothorax to about the ninth abdominal segment and remained connected at the posterior end of the body (Fig. 1L). A larva was seen struggling to shed the cuticle, which was in an almost perpendicular position to the body (Fig. 1J). Old exuviae were seen in exuvial chambers (Fig. 1D) and the shape of their exuvial splits was identical to those observed during the moult, although occasionally the dorsal and ventral surfaces of old exuviae were not connected posteriorly.

\section{Cameraria spp. (Lepidoptera: Gracillariidae)}

Blotch mines contained either an individual larva (mainly on Quercus; Fig. 2C), or up to 10 or more (mainly on Ostrya; Fig. 2B); in the latter case all the larvae were approximately of the same size and most likely siblings. The larval head was clearly visible (Figs $2 \mathrm{E}-\mathrm{G})$ and not retracted into the prothorax. More than one mine was frequently found on the same leaf (Fig. 2B). The morphologically peculiar tissue-feeding larval instars occasionally recorded for some Gracillariidae (Kumata, 1978) were not observed. Pupation took place inside the mine and the silk cocoon also contained, in addition to the pupa, the shed cuticle of the larva that spun the cocoon (Fig. 2P). The shed cuticle of the last sap-feeding instar was frequently observed wedged between the cocoon and the leaf surface (Fig. 2N). The larva that spins the cocoon was often seen with its posterior end attached to the internal surface of the cocoon and quickly moving its head in a rapid pendulum-like movement presumably distributing the threads of silk produced by its labial glands. There were at least three distinct layers of silk in the wall of the cocoon (Fig. 2P). Abandoned cocoons were almost universally pierced by the acute apex at the anterior end of pupae, so the latter partially protruded from a cocoon prior to adult enclosion, which is characteristic of Gracillarioidea (Davis \& Robinson, 1999). No adults were observed in the field. When detected, mines of Cameraria were often found in large numbers, sometimes infesting about $50 \%$ of the leaves of a host plant viewed from the ground.

One sap-feeding larva was observed and photographed during moulting (Figs 2H, I, K-M). During this process the head of the exuviae remained complete, unlike the rest of the shed cuticle, and slid forward (Figs $2 \mathrm{H}, \mathrm{I}, \mathrm{K}$ ). The rest of the shed cuticle was split laterally on both sides from the thorax to about half way along the abdomen (Figs 2L, M). The dorsal and ventral parts of the exuviae progressively became detached from the emerging larva and gradually slid posteriorly and concertinaed (Figs 2L, $\mathrm{M})$. Numerous and often peculiarly bent exuviae of sapfeeding larvae (Fig. 2N) were observed in mines of which the head capsule was either completely detached (Fig. 2O) or weakly connected to the rest of the shed cuticle.

Exuviae of the spinning larvae were frequently observed inside inhabited (Fig. 2P) or abandoned cocoons. These exuviae were remarkably different from those of the preceding instars in being opened dorsomedially rather than laterally and having head capsule attached to the remaining exuviae and opened along the lines of weakness. These dry exuviae were markedly twisted and distorted and, therefore, location of the exuvial split was not immediately obvious. This difficulty was solved by employing a morphological marker of long 

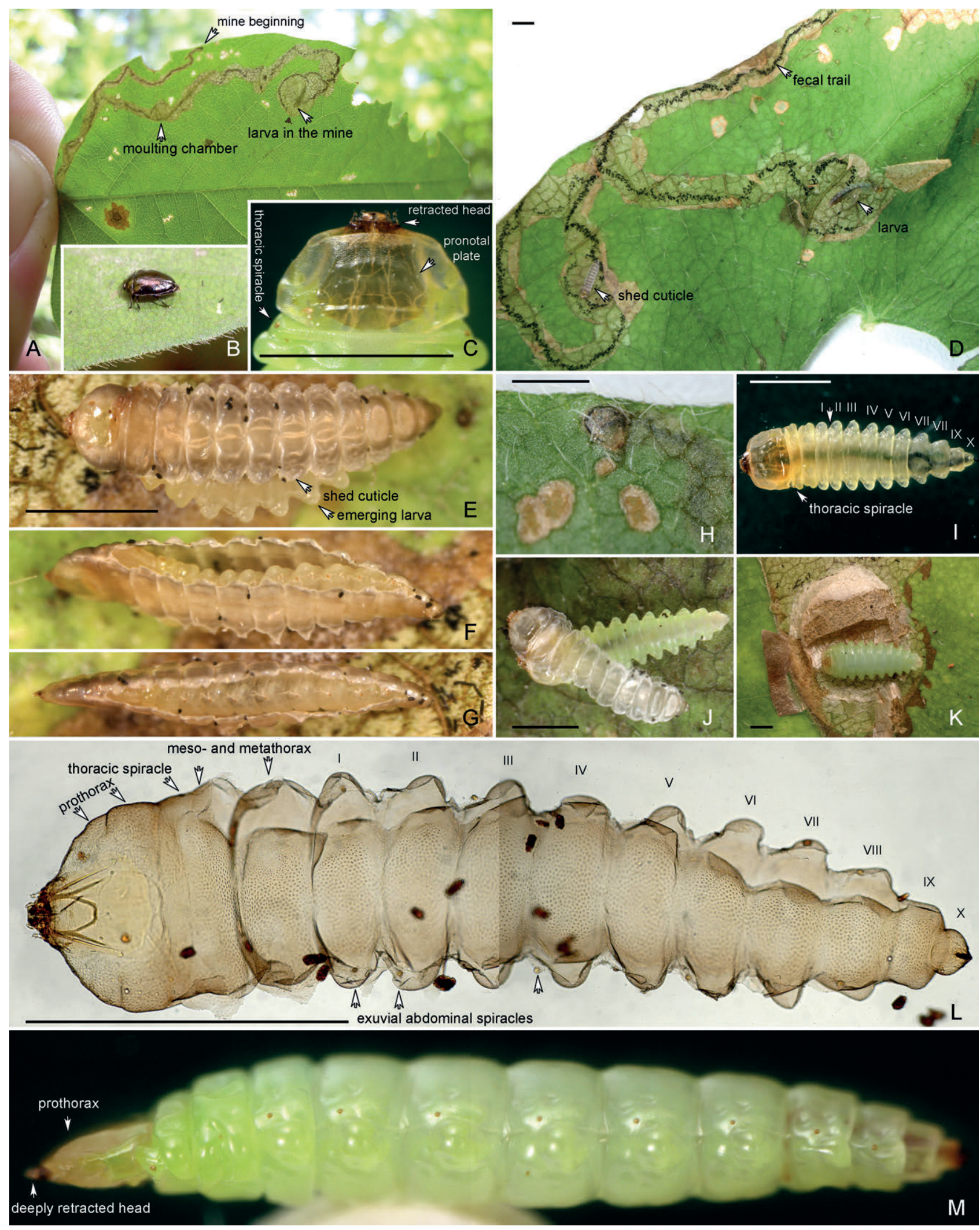

Figs 1A-M. Pachyschelus laevigatus (Coleoptera: Buprestidae). A - leaf of Desmodium glutinosum with linear larval mine; B adult beetle; $\mathrm{C}$ - larva, anterior body, viewed dorsally; D - dorsally opened linear mine showing parasitized larva and a shed cuticle; $\mathrm{E}-\mathrm{G}$ - larva in the process of moulting, viewed dorsally (E), latero-ventrally (F) and laterally $(\mathrm{G})$; $\mathrm{H}$ - oviposition site on ventral surface of a leaf with empty chorion, scars where female nibbled the surface of the leaf and beginning of the larval mine; I - larva, viewed ventrally; J - newly moulted larva shedding cuticle through two lateral exuvial splits; $\mathrm{K}$ - mature larva in opened chamber, viewed dorsally; $\mathrm{L}$ - shed cuticle, viewed dorsally; $\mathrm{M}$ - larva, viewed laterally. Scale bars: $1 \mathrm{~mm}$. 

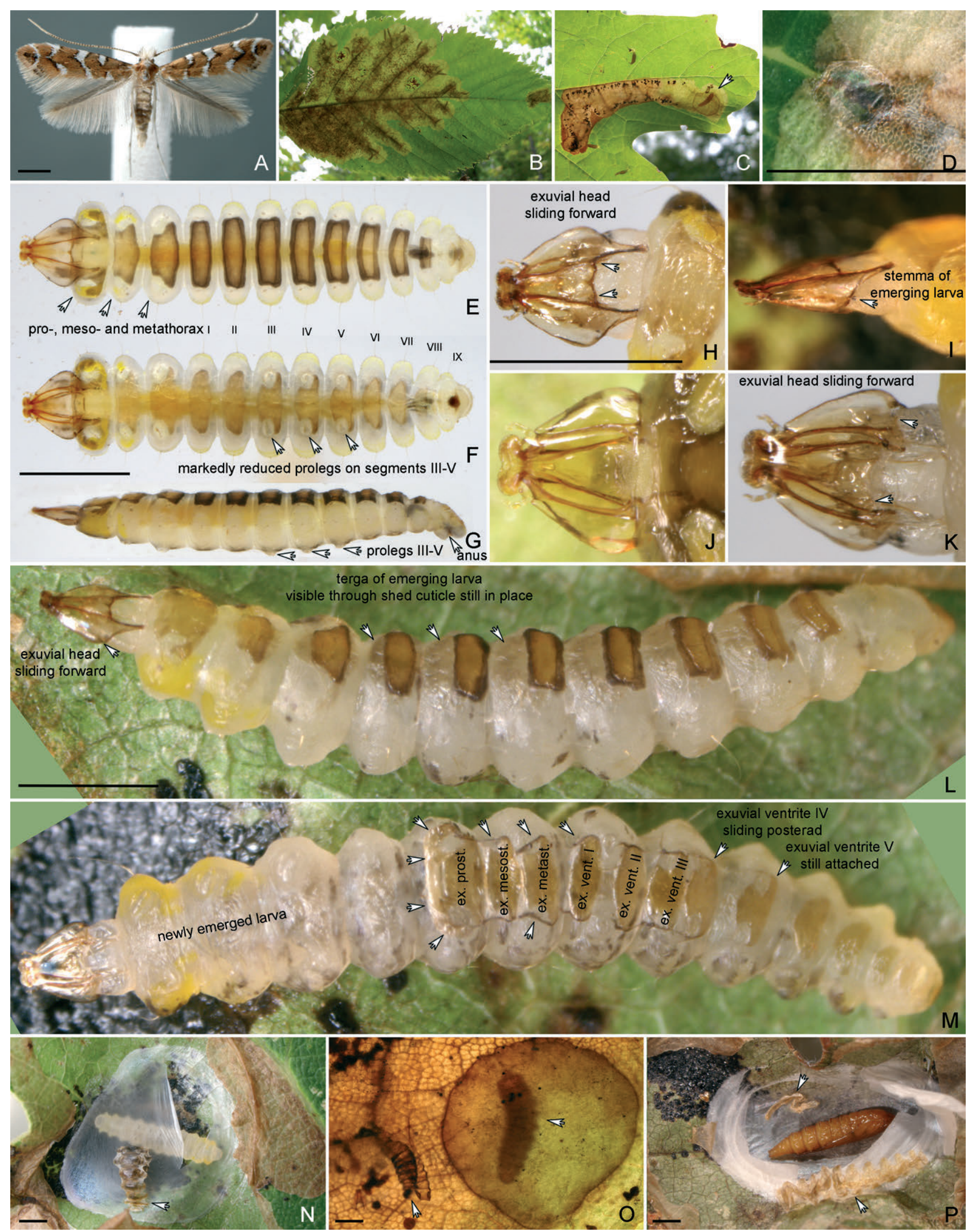

Figs 2A-P. Cameraria spp. (Lepidoptera: Gracillariidae). A - C. gaultheriella, adult; B - two communal blotch mines on Ostrya virginiana; $\mathrm{C}$ - individual blotch mine on Acer sp. with spinning larva inside a cocoon; $\mathrm{D}$ - oviposition site and beginning of the larval mine; E-G - sap-feeding larva, viewed dorsally (E), laterally $(\mathrm{F})$ and ventrally $(\mathrm{G})$; $\mathrm{H}-\mathrm{J}$ - process of moulting showing the entire exuvial head detaching from the rest of the exuviae and sliding forward, viewed dorsally (H), laterally (I) and ventrally (J); K - larval head, viewed ventrally; L-M - moulting in process showing the newly emerging larva and its shed cuticle transversely divided into the exuvial head and rest of the exuviae and being shed forward and backward, respectively; rest of the exuviae is 
lateral tergal setae easily detectable on the sap-feeing larva and the shed cuticles.

\section{DISCUSSION}

\section{Great antiquity and high conservatism of the moulting process}

Ecdysis, i.e., the process of shedding a cuticle in order to grow, is supposedly an evolutionary novelty (= synapomorphy) and highly characteristic attribute of all Ecdysozoa. This group includes Arthropoda, Nematoda, Onychophora, a few smaller phyla (Dunn et al., 2008) and possibly the extinct xenusians (Bergström \& Hou, 2002), all of which moult. As far as it is known, the basic plan of the moulting process is highly conserved and significant differences are found only among the major phylogenetic lineages, with the most diverse in this respect the acariform mites and even more so the trilobites (Norton \& Kethley, 1994, and Brandt, 2002, respectively). There are relatively few detailed comparative studies of the exuvial strategies within the ecdysozoan subgroups (Tetlie et al., 2008 on sea scorpions and references therein) and they further corroborate the highly conservative nature of the moulting process. In Insecta, including the Holometabola clade, which contains all known leaf-miners, the newly emerging larvae almost universally leave the shed cuticle through a single exuvial opening along the dorso-medial thoracic and sometimes abdominal line; the process is usually further facilitated by various dorsal splits in the exuvial head capsule (Fig. 3).

\section{Leaf-mining in insects}

The following discussion of leaf mines and leaf-mining insects is mainly based on the classical 1951 summary by the renowned German expert Erich Martin Hering (1893-1967), which is published in English. Recently this matter was further elucidated and brought up to date in a comprehensive review by Santiago-Blay (2004). Although it focused specifically on the leaf beetles (Chrysomelidae), the latter work serves as an all-inclusive review of leaf-mining in insects. All facts and observations discussed below, unless obviously new or explicitly attributed to a specific source, can be found, and their origin traced, in the review by Santiago-Blay (2004).

In the Insecta, leaf mining is recorded only in the four largest holometabolan orders. Some 10,000 species of Coleoptera, Lepidoptera, Diptera and Hymenoptera are leaf-miners, which is a mere $2 \%$ of their total species richness. As far as it is known, it is only the larvae and never adults that are leaf-miners. Most leaf mines are recorded on eudicotyledons, although representatives of all the main lineages of vascular plants are mined by insects. The earliest fossil records of gracillariid leaf mines are from the Cretaceous (about 100 millions years ago; Labandeira et al., 1994).

In Coleoptera and Diptera the leaf-mining lifestyle undoubtedly evolved several times and was likely secondarily lost in numerous unrelated lineages. In beetles it is recorded among Buprestidae, Ptinidae, Nitidulidae, Cerambycidae (Martin, 2000), Chrysomelidae, various Curculionoidea and possibly Mordellidae. The phenomenon apparently evolved only once in Buprestidae (Agrilinae: Trachydini; provided this tribe is a clade, which has not been adequately tested), Ptinidae and Cerambycidae; in the two latter families only a single species is known to mine. In Chrysomelidae and Curculionoidea leaf mining apparently evolved a number of times and is currently recorded in a wide variety of presumably unrelated lineages. Similarly in Diptera, leaf mining seems also to have evolved at least 25 times and is currently recorded in about 17 families.

In Hymenoptera only about 100 species of Symphyta are reported as leaf-miners and all belong to three families of the saw-fly superfamily Tenthredinoidea: Tenthridinidae, Argidae and Pergidae. Although members of this relatively "basal" lineage are leaf-miners, it does not seem to be the ground plan feature of this order. The first hymenopteran larva was hypothesised by Sharkey (2007) to be eruciform (caterpillar-like) and forage externally on exposed vegetation. Present-day hymenopteran leafminers indeed retain much of the eruciform larval body, being relatively little flattened and possessing thoracic legs (Figs 3A-D). It seems likely, therefore, that the morphological and presumably all other adaptations to leafmining in Hymenoptera are relatively less extensive than in many other leaf-miners

In Lepidoptera, however, leaf-mining may have appeared very early in the history of the order. Leaf mining is common in numerous "basal" moth lineages and is recorded in about 34 families but with most of the leaf-mining species in the Gracillariidae (Davis \& Robinson, 1999; Davis \& Wagner, 2005; Davis \& De Prins, 2011). Currently it is thought that the larvae of the extant leaf-mining Heterobathmiidae resemble most closely the putative lepidopteran larval ground plan (Kristensen \& Nielsen, 1983). This family is the hypothetical sistergroup of the entire Glossata and, therefore, their common ancestor is close to the lepidopteran stem species (Kristensen, 1997). The larvae of Heterobathmiidae, however, are not highly specialized morphologically, have well developed thoracic legs and possibly the ancestral complement of seven stemmata. They also can leave their mine and initiate another one in another leaf (Kristensen $\&$ Nielsen, 1983). Thus the leaf-mining way of life of

additionally split laterally on both sides along thorax and at least the first three abdominal segments with the dorsal half still overlaying the corresponding larval body segments, while the ventral half is already partly shed and concertinaed over abdominal segments II-IV, viewed dorso-laterally (L) and ventrally (M); N - mine opened from above and exposing spinning larva hanging upside down from the cocoon roof with shed cuticle of the last sap-feeding larval instar positioned above; $\mathrm{O}$ - cocoon with spinning larva inside visible in an undamaged mine with laterally split shed cuticle of the last sap-feeding instar and its detached head just outside the cocoon; P - pupa in cocoon with shed cuticle of spinning larva inside and that of last instar sap-feeding outside the cocoon; head of the latter is detached. Scale bars: $1 \mathrm{~mm}$. 


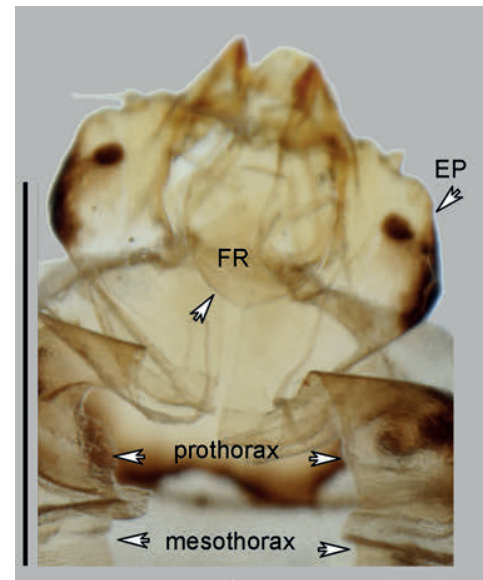

A
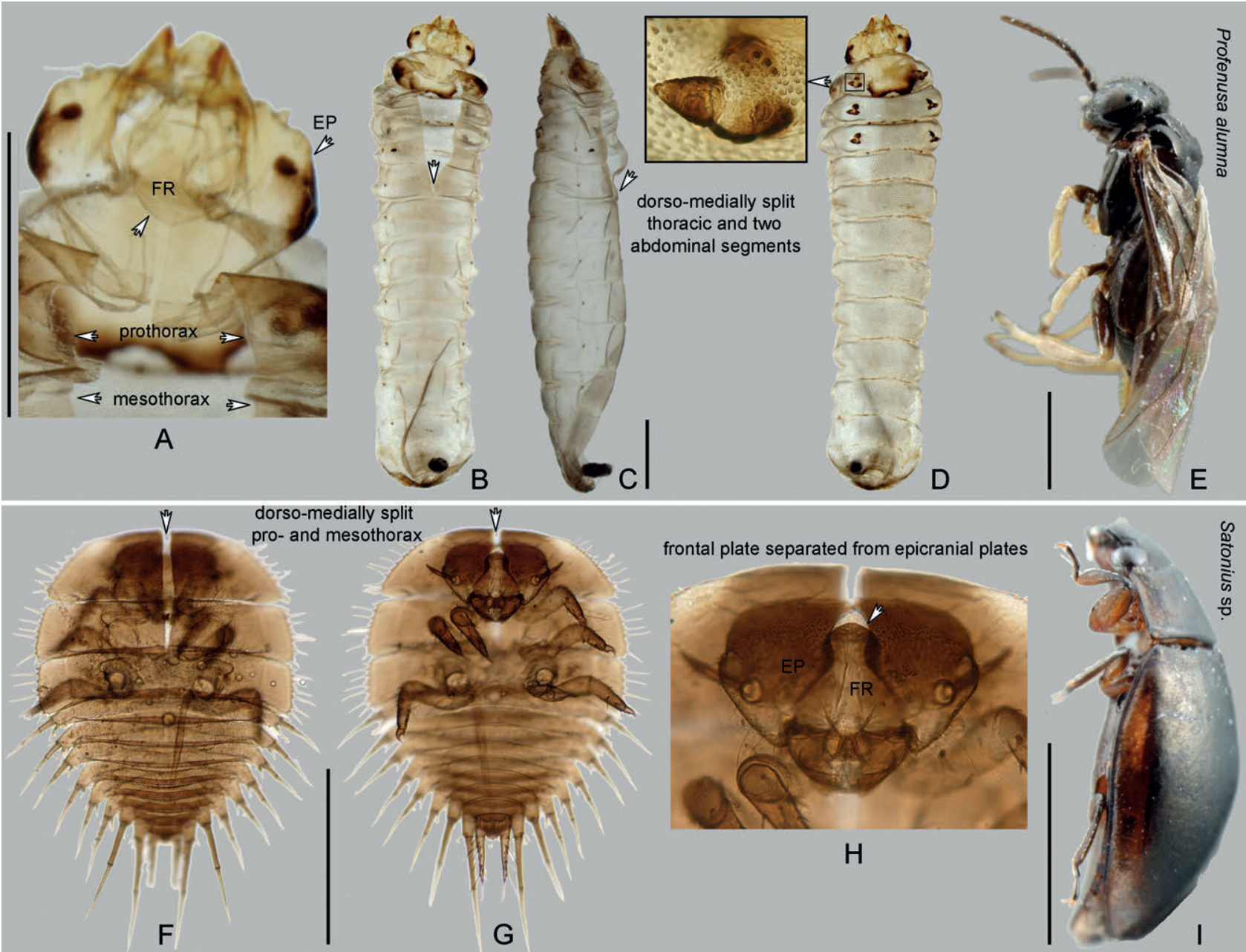

$\mathrm{H}$
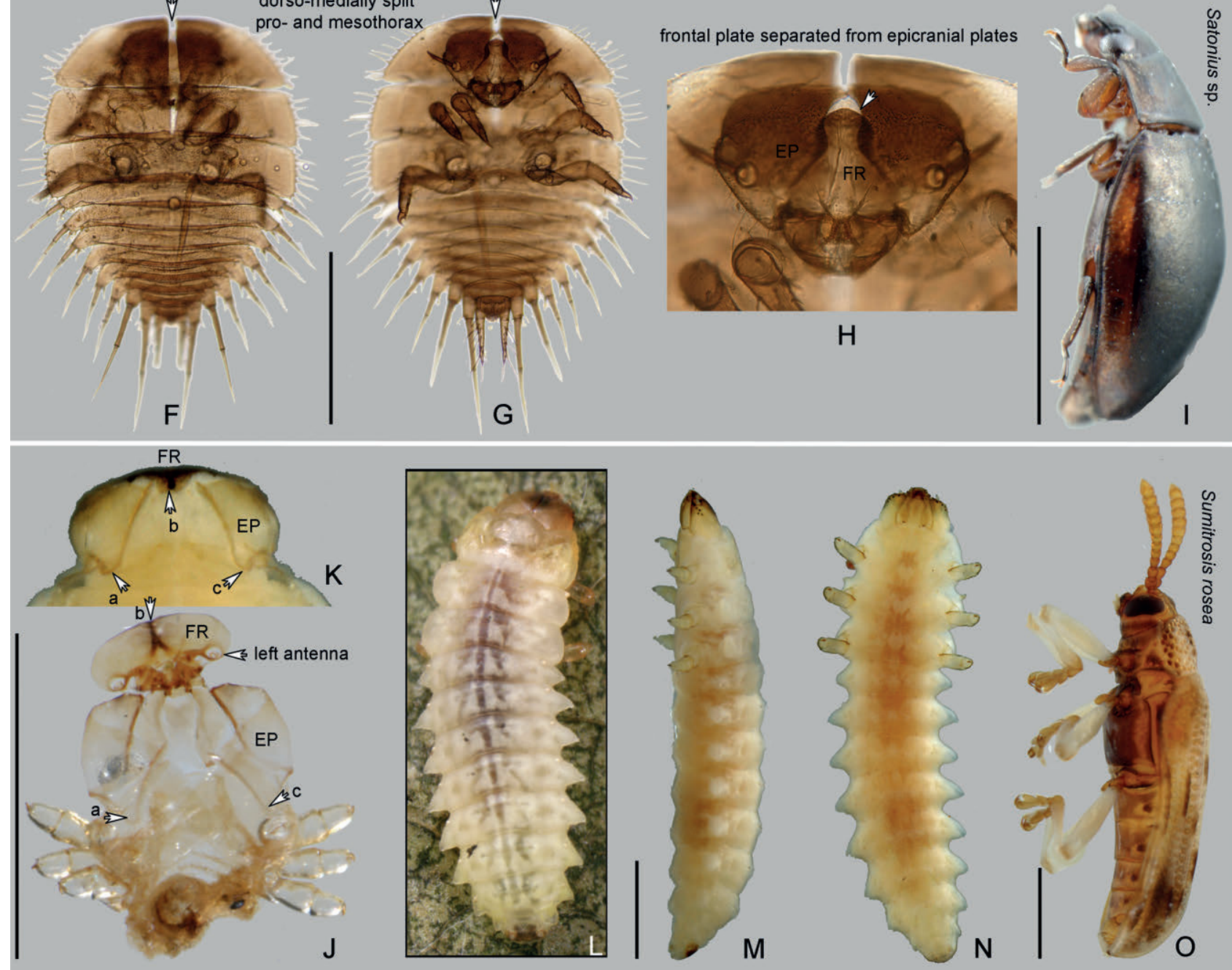

Figs 3A-O. Common and unspecialized types of moulting by means of a dorso-medial exuvial split in leaf-mining (A-E; J-O) and free-living (F-I) holometabolous larvae. A-E - Profenusa alumna (Hymenoptera: Tenthredinidae): A - head with parts of pro- and mesothorax, viewed dorsally; B-D - shed cuticle maintaining body shape and removed from a mine, viewed dorsally (B), from left side (C) and ventrally (D) (insert showing right fore-leg, viewed ventrally); E - adult, viewed from left side. F-I - Satonius spp. (Coleoptera: Torridincolidae): $\mathrm{F}-\mathrm{G}$ - shed cuticle removed from the surface of a rock in a hygropetric habitat inhabited by the beetle, viewed dorsally $(\mathrm{F})$ and ventrally $(\mathrm{G}) ; \mathrm{H}$ - exuvial head and part of prothorax showing dorsal separation of parietal and epicranial plates, viewed ventrally; I - adult, viewed from left side. J-O - Sumitrosis rosea (Coleoptera: Chrysomelidae): J - shed cuticle with collapsed abdominal and thoracic segments and head capsule fully open along dorsal ecdysial lines, removed from a leaf mine and viewed ventrally (arrowed points "a", "b" and "c" denote corresponding points in J and K); K - larval head in the process of moulting showing dorso-medial thoracic exuvial split and epicranial plates opening laterally, viewed dorsally; L-N - live (L) and dead $(\mathrm{M}, \mathrm{N})$ larvae, viewed dorsally $(\mathrm{L})$, from left side $(\mathrm{M})$ and ventrally $(\mathrm{N})$; O - adult, viewed from left side. Scale bars: $1 \mathrm{~mm}$. 
numerous extant Lepidoptera might indeed be a plesiomorphic condition inherited from a common ancestor.

\section{Does leaf-mining "impose" the lateral exuvial split?}

Although many successful leaf miners moult normally, the lateral splitting of exuviae is clearly advantageous particularly in those leaf miners whose body size approaches the upper limits imposed by the height of the mine; in effect, they live in two-dimensional space. These larvae are likely to benefit from being able to moult without raising their body in the already fully occupied vertical dimension of a mine. This is achieved by employing two somewhat separate moulting peculiarities: (1) shedding the exuvial head in toto, i.e., without splitting along the ecdysial lines, and (2) splitting the shed cuticle of the body not dorsally, but laterally. The peculiarity of the entire head capsule shed in toto, even though not restricted to the leaf-miners, might be a greater mechanical challenge for larvae than the lateral splitting of the thoracic and abdominal exuviae. The main difference in Cameraria is that it sheds the exuviae of the head separately from the rest of the cuticle, whereas in Pachyschelus the head exuvial cuticle remains firmly attached to that of the body. These differences may stem from the fact that the head of larvae of Cameraria is wellsclerotized and fully exposed (Figs $2 \mathrm{E}-\mathrm{G}, \mathrm{I}$ ) whereas that of larvae of Pachyschelus is retracted into the thorax and weakly sclerotized (Fig 1C, I, L, M).

Leaf-mining does not necessarily affect the moulting strategy as profoundly as described above. A tenthredinid saw-fly, Profenusa (Figs 3A-E), and a cassidine leafbeetle, Sumitrosis (Figs 3J-O), moult in the usual way and also retain other non-specialized features such as less flattened bodies and presence of articulated legs. These observations suggest that the lateral exuvial split might be seen as a relatively advanced adaptation to leaf-mining.

\section{Are lateral exuvial splits a rare phenomenon and where to look for them?}

At present only two newly reported instances of larval lateral moult are known, although their apparent rarity possibly only reflects the lack of data. The similarity of insect moulting appears to be universally (and somewhat silently) accepted and, therefore, the details of moulting are not recorded in any of the papers on leaf-mining consulted. This is remarkable, as both Cameraria moths and Trachyini jewel-beetles occur in Europe and North America, two reputed centers of entomological science, and both genera are often studied and cited. The present paper will hopefully provoke more focused attention on the details of moulting of leaf miners, particularly those with obvious signs of significant morphological adaptations, such as extreme body flattening and lack of articulated legs. Mines should be searched for recently shed exuviae (Fig. 1L). Such a simple method is expected to generate numerous new records of the lateral exuvial splits, particularly in those taxa most closely related to the above species. The character may also prove to be of taxonomic importance.
And, finally, which taxa are most likely to include other laterally moulting leaf miners? Lepidoptera should seemingly have the most, since the leaf-mining lifestyle might be the ancestral feature of many of the present-day species. Indeed moth larvae appear to be better morphologically adapted for leaf-mining than the majority of beetles and hymenopterans. Among them the gracillariid genera Marmara Clemens, 1863 and Dendrorycter Kumata, 1978 exhibit another highly bizarre unique moulting adaptation of apolysis which is not accompanied by ecdysis. This refers to the phenomenon of having a relatively brief and inactive transitional (quiescent) larval instar between the last sap-feeding and cocoon-spinning instars (Wagner et al., 2000; Guillén et al., 2001). This transitional instar does not shed the cuticle of the last sapfeeding mining instar but remains inside it and can actually be seen through it (Wagner et al., 2000). When the subsequent spinning instar emerges, it has to shed exuviae of both the last spinning and the preceding (transitional) instars (Guillén et al., 2001). Gracillariid species with a transitional instar are not restricted only to mining leaves, but also mine the upper epidermal layer of any photosynthetic tissues such as roots, stems and fruits of a remarkable variety of plants including grapefruit (Citrus L., Rutaceae), cacti (Cactaceae) and Douglas-fir (Pseudotsuga Carrière, Pinaceae).

As for Diptera, this order includes many leaf-miners of highly peculiar shapes and it is unlikely that they have evolved lateral exuvial splits. The reason might lay in the deeply retracted and much reduced mouthparts (Hering, 1951), which were presumably already in place before the multiple origin of leaf-mining (see dipteran phylogeny in Yeates et al., 2007). This potential constraint of already having retracted mouthparts possibly resulted in the evolution in leaf-miners of the most peculiar and seemingly unparalleled alternative side-wise larval feeding position. The larvae of all leaf-mining Diptera lay on their side in mines and feed not in front of them, which is impossible because of their highly reduced and deeply retracted mouthparts, but to either side. The side-feeding larvae frequently alternate their position by rotating their body $180^{\circ}$ along the longitudinal axis to feed on the opposite side of the mine. As their anal opening is located ventrally, faeces are alternatively deposited in masses on the left and right side of the mine in a regular and alternating manner, characteristic of dipteran miners.

ACKNOWLEDGEMENTS. S. Laplante (Ottawa, Canada) triggered this project by calling my attention to Desmodium plants mined by Pachyschelus larvae. For years he had known of a place where this jewel-beetle bred and identified for me both the beetle and its host plant. Furthermore, he showed me the nearby Bristol Mine locality, where the first mines of Cameraria were seen and collected. D.R. Davis (Washington, DC, USA) identified my lepidopteran leaf-miners as those of Cameraria, sent me literature on the biology of larval Gracillariidae and critically read the manuscript of this paper prior to submission. J.-F. Landry and V. Nazari (both Ottawa, Canada) directed me to the literature on Lepidopteran leaf-miners and provided the depicted C. gaultheriella adult (Fig. 2A). N.P. Kristensen (Copenhagen, Denmark) instructed me in the evolutionary significance of leaf- 
mining in the broader context of Lepidopteran phylogeny. P. Švácha (České Budějovice, Czech Republic) called my attention to the single record of a leaf-mining Cerambycidae beetle (Martin, 2000). H. Goulet (Ottawa, Canada) identified the exuviae of the sawfly Profenusa alumna. J. Bergström (Stockholm, Sweden) told me how the extinct onychophore-like xenusians moulted. C. Schmidt (Ottawa, Canada) called my attention to the peculiarities of Marmara moult and reviewed this MS prior to submission. Results reported in this paper were presented at the 2011 Immature Beetle Meeting in Prague (http://www. cercyon.eu/IBM/IBM_2011.htm), author's participation at which was in part supported by the Alexander von Humboldt Foundation (www.avh.de).

\section{REFERENCES}

Bergström J. \& Hou X.-G. 2002: Cambrian Onychophora or Xenusians. - Zool. Anz. 240: 237-245.

BRANDT D.S. 2002: Ecdysial efficiency and evolutionary efficacy among marine arthropods: implications for trilobite survivorship. - Alcheringa 26: 399-421.

Davis D.R. \& De Prins J. 2011: Systematics and biology of the new genus Macrosaccus with description of two new species (Lepidoptera, Gracillariidae). - Zookeys 98: 29-82.

Davis D.R. \& Robinson G.S. 1999: Tineoidea and Gracillarioidea. In Kristensen N.P. (ed.): Handbook of Zoology, Part 35, Lepidoptera, Vol. 1. De Gruyter, Berlin, pp. 91-107.

DAvis D.R. \& WAGNER D.L. 2005: Biology and systematics of the Neotropical leafminer genus Eucosmophora (Lepidoptera: Gracillariidae). — Trop. Lepidopt. 13[2002]: 1-40.

Dunn C.W., Hejnol A., Matus D.Q., Pang K., Browne W.E., Smith S.A., Seaver E., Rouse G.W., Obst W., Edgecombe G.D., Sørensen M.V., Haddock S.H.D., Schmidt-Rhaesa A., Okusu A., Kristensen R.M., Wheeler W.C, Martindale M.Q. \& GiRIBET G. 2008: Broad phylogenomic sampling improves resolution of the animal tree of life. - Nature 452: $745-749$.

Guillén M., Davis D.R. \& Heraty J.M. 2001: Systemtics and biology of a new, polyphagous species of Marmara (Lepidoptera: Gracillariidae) infesting grapefruit in the southwestern United States. - Proc. Entomol. Soc. Wash. 103: 636-654.

Hering E.M. 1951: Biology of the Leaf Miners. W. Junk, The Hague, $420 \mathrm{pp}$.
KRISTENSEN N.P. 1997: Early evolution of the Trichoptera + Lepidoptera lineage: phylogeny and the ecological scenario. - Mém. Mus. Natn. Hist. Nat. (Zool.) 173: 253-271.

KRISTENSEN N.P. \& NIELSEN E.S. 1983: The Heterobathmia life history elucidated: Immature stages contradict assignment to suborder Zeugloptera (Insecta, Lepidoptera). - $Z$. Zool. Syst. Evol.-Forsch. 21: 101-124.

Kumata T. 1978: A new stem-miner of alder in Japan, with a review of the larval transformation in the Gracillariidae (Lepidoptera). - Insecta Matsum. (N.S.) 13: 1-27.

Labandeira C.C., Dilcher D.L., Davis D.R. \& Wagner D.L. 1994: Ninety-seven million years of angiosperm-insect association: paleobiological insights into the meaning of coevolution. - Proc. Natn. Acad. Sci. USA 91: 12278-12282.

Lawrence J.F., Ślipiński A., Seago A.E., Thayer M.K., Newton A.F. \& Marvaldi A.E. 2011: Phylogeny of the Coleoptera based on morphological characters of adults and larvae. Ann. Zool. (Warszawa) 61: 1-217.

MARTIN N.A. 2000: A longicorn leaf miner, Microlamia pygmaea (Coleoptera: Cerambycidae: Lamiinae) found in New Zealand. - N. Z. Entomol. 23: 86.

Norton R.A. \& Kethley J.B. 1994: Ecdysial cleavage lines of acariform mites (Arachnida, Acari). - Zool. Scripta 23: 175-191.

Tetlie O.E., Brandt D.S. \& Briggs D.E.C. 2008: Ecdysis in sea scorpions (Chelicerata: Eurypterida). - Palaeogeogr. Palaeoclimatol. Palaeoecol. 265: 182-194.

Santiago-Blay J.A. 2004: Leaf-mining chrysomelids. In Jolivet P., Santiago-Blay J.A. \& Schmitt M. (eds): New Developments in the Biology of Chrysomelidae. SPB Academic Publishing, The Hague, pp. 1-83.

SHARKEY M.J. 2007: Phylogeny and classification of Hymenoptera. - Zootaxa 1668: 521-548.

Wagner D.L., Loose J.L., Fitzgerald T.D., de Benedictis J.A. \& DAvis D.R. 2000: A hidden past: hypermetamorphic development of Marmara arbutiella (Lepidoptera: Gracillariidae). - Ann. Entomol. Soc. Am. 93: 59-64.

Yeates D.K., Wiegmann B.M., Courtney G.W., Meiet R., LAMBKIN C. \& PAPE T. 2007: Phylogeny and systematics of Diptera: Two decades of progress and prospects. - Zootaxa 1668: $565-590$

Received November 21, 2011; revised and accepted October 29, 2012 